\title{
Antileishmanial Activity and Influence on Mitochondria of the Essential Oil from Tagetes lucida Cav. and Its Main Component
}

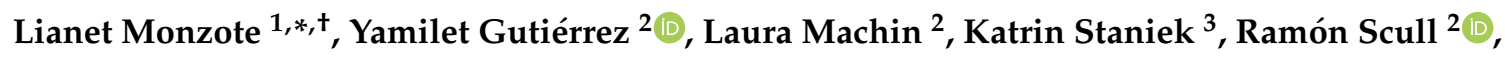 \\ Prabodh Satyal ${ }^{4}$, Lars Gille ${ }^{3}$ D and William N. Setzer $4,5, *,+(D)$ \\ 1 Parasitology Department, Institute of Tropical Medicine "Pedro Kouri", Havana 17100, Cuba \\ 2 Department of Pharmacy, Institute of Pharmacy and Food, Havana University, Coronela, \\ La Lisa 17100,Cuba; ygutierrez@infomed.sld.cu (Y.G.); laura@ifal.uh.cu (L.M.); rscull@ifal.uh.cu (R.S.) \\ 3 Institute of Pharmacology and Toxicology, Department of Biomedical Sciences, \\ University of Veterinary Medicine, Veterinärplatz 1, A-1210 Vienna, Austria; \\ Katrin.Staniek@vetmeduni.ac.at (K.S.); Lars.Gille@vetmeduni.ac.at (L.G.) \\ 4 Aromatic Plant Research Center, 230 N 1200 E, Suite 100, Lehi, UT 84043, USA; psatyal@aromaticplant.org \\ 5 Department of Chemistry, University of Alabama in Huntsville, Huntsville, AL 35899, USA \\ * Correspondence: monzote@ipk.sld.cu (L.M.); wsetzer@chemistry.uah.edu (W.N.S.); \\ Tel.: +1-256-824-6519 (W.N.S.) \\ + Research Network Natural Products against Neglected Diseases (ResNetNPND).
}

Received: 10 June 2020; Accepted: 26 July 2020; Published: 29 July 2020

check for updates

\begin{abstract}
Current antileishmanial drugs are toxic, expensive, and resistance to them has emerged. Several studies have focused on natural products as alternatives. In the present work, the chemical composition, in vitro antileishmanial activity, cytotoxicity effects, and the influence on mitochondrial function of the essential oil from Tagetes lucida Cav. was determined, as well its main compound estragole. Forty-nine compounds were detected in the oil by gas chromatography-mass spectrometry (GC-MS), of which estragole was the main constituent (97\%). The oil showed inhibition of the promastigotes of L. tarentolae and L. amazonensis $\left(\mathrm{IC}_{50}=61.4\right.$ and $118.8 \mu \mathrm{g} / \mathrm{mL}$, respectively), decreased oxygen consumption of L. tarentolae, disrupted mitochondrial membrane potential in L. amazonensis, inhibitory activity on the intracellular amastigote of L. amazonensis $\left(\mathrm{IC}_{50}=14.2 \pm 1.6 \mu \mathrm{g} / \mathrm{mL}\right.$ ), and cytotoxicity values ranging from 80.8 to $156 \mu \mathrm{g} / \mathrm{mL}$ against murine macrophages and J774 cells. Estragole displayed higher activity on promastigotes ( $\mathrm{IC}_{50}=28.5$ and $25.5 \mu \mathrm{g} / \mathrm{mL}$, respectively), amastigotes $\left(\mathrm{IC}_{50}=1.4 \pm 0.1 \mu \mathrm{g} / \mathrm{mL}\right.$ ), and cytotoxicity values ranging from 20.6 to $14.5 \mu \mathrm{g} / \mathrm{mL}$, respectively, while on mitochondria, it caused a decrease of the membrane potential but did not inhibit oxygen consumption. The potential antileishmanial activity of the essential oil from T. lucida and estragole makes these compounds favorable candidates for exploration in further studies.
\end{abstract}

Keywords: Leishmania; Tagetes lucida; essential oil; estragole; mitochondria

\section{Introduction}

The intracellular protozoan parasites of the genus Leishmania are the causative agents of leishmaniasis, a vector-borne disease of major public health concern in tropical and subtropical regions. Approximately, 0.7-1 million new cases of leishmaniasis occur per year and 12 million infected people worldwide are reported from nearly 100 endemic countries. The clinical manifestations of leishmaniasis are highly variable with two main clinical forms-cutaneous leishmaniasis and visceral leishmaniasis, which range from self-healing localized cutaneous lesions to life-threatening disseminated visceral disease [1,2]. 
So far, the development of an effective Leishmania vaccine for humans with effective immune protection has not yet been achieved [3]. As alternatives to combat the disease progression, there are several known antileishmanial chemotherapeutic drugs, such as derivatives of pentavalent antimonials, amphotericin B, pentamidine, paromomycin, and miltefosine. However, several drawbacks during the treatment regimen have been observed, including toxic effects, prolonged administration, parasite resistance, and high costs [4]. Additionally, leishmaniasis is considered to be a "Neglected Tropical Disease" and current treatment regimens are often too expensive or unavailable in developing countries where the disease is prevalent. In this context, there is an urgent demand to accelerate the development of more effective treatment options against leishmaniasis and plant-based treatment options, such as essential oils, should be further explored.

In particular, several plants from the Asteraceae family have provided some lead compounds against Leishmania spp. [5,6]. Specifically, Tagetes lucida Cav. is a perennial plant native to Central America. It is used as a culinary herb and some pharmacological therapeutic effects have been reported, including tranquilizing properties [7], antidepressant activity [8], and analgesic activity [9]. However, to our knowledge, the antileishmanial effect of this plant has not been studied. Therefore, the aim of the present study was to determine the chemical composition, in vitro antileishmanial activity, cytotoxicity effects, and influence on mitochondrial function of the essential oil (EO) from the leaves of T. lucida. In addition, the antileishmanial potential of the main compound estragole was also studied (the Materials and Methods are available as Supplementary Materials).

\section{Results and Discussion}

The chemical analysis revealed the EO from aerial parts of T. lucida collected in Havana, Cuba, to be a mixture of aromatic compounds, in which forty-nine compounds were detected (see Supplementary Materials Table S1). Methyl chavicol, also known as estragole or $p$-allylanisole, was the main component with $97 \%$, approximately. Our result corroborates a report by Regalado et al., [10], which identified forty volatile compounds and estragole was the major constituent with a $96.8 \%$ composition. The analysis of EO from T. lucida plants from Egypt [11,12], Colombia [13], and Costa Rica [14] also showed that the main component identified was estragole, corresponding to more than $80 \%$ of the entire composition. Therefore, it appears that this chemotype is highly predominant, for which this plant has been recommended as a relevant source to obtain pure estragole [14]. Nevertheless, a different quantitative and qualitative composition has also been documented in plants collected from Mexico [15], in which the main compound was geranyl acetate (49.9\%). A perusal of the literature reveals at least four different chemotypes of T. lucida based on essential oil composition: (1) an estragole-dominated chemotype [10-14], (2) an estragol/anethol chemotype [15,16], (3) a methyl eugenol chemotype [17], and (4) a geranyl acetate-rich chemotype [17,18]. The phenylpropanoid estragole is found in numerous EOs and is known to possess different pharmacological properties, such as antifungal [19], antiparasitic [20,21], and anti-inflammatory [22] activity.

In the biological assays, two Leishmania species were used, L. tarentolae promastigotes (LtP) as a non-pathogenic leishmaniasis model to use in open systems and L. amazonensis promastigotes (LaP) as an infective model. In the antipromastigote assay, the EO from T. lucida showed higher activity $(p<0.05)$ against $\mathrm{LtP}\left(\mathrm{IC}_{50}=61.4 \pm 2.4 \mu \mathrm{g} / \mathrm{mL}\right)$ compared with the $\mathrm{LaP}$ model $\left(\mathrm{IC}_{50}=118.8 \pm 1.2 \mu \mathrm{g} / \mathrm{mL}\right)$. Estragole provided similar $\mathrm{IC}_{50}$ values $(p>0.05)$ in both Leishmania species used $\left(\mathrm{IC}_{50} \mathrm{LtP}=28.5 \pm 1.0 \mu \mathrm{g} / \mathrm{mL}\right.$ and $\left.\mathrm{IC}_{50} \mathrm{LaP}=25.5 \pm 3.3 \mu \mathrm{g} / \mathrm{mL}\right)$ and higher activity $(p<0.05)$ with respect to the EO. Although the antileishmanial performance of T. lucida has not been evaluated earlier, other species of the same genus have displayed antileishmanial activity, such as the methanol extract of Tagetes minuta L., which showed an $\mathrm{IC}_{50}$ of $30.1 \mu \mathrm{g} / \mathrm{mL}$ against L. infantum [23]. Regarding estragole, previous studies of antileishmanial activity have not been reported; however, the antiprotozoal potential of estragole has been documented in the same range against Plasmodium falciparum $\mathrm{IC}_{50}=30.7 \mu \mathrm{g} / \mathrm{mL}$ [20] and Eimeria tenella $\mathrm{IC}_{50}=22 \mu \mathrm{g} / \mathrm{mL}[21]$. 
In parallel, there are additional reports indicating other biological activities of estragole. Khan et al. [19] reported that this compound is able to induce apoptosis at low concentrations as a result of oxidative stress and mitochondrial dysfunction, which could contribute to cell death in Candida albicans. However, the possible mechanism of its leishmanicidal action remains unknown so far. Preliminarily, we evaluated the influence of the EO from T. lucida and estragole on Leishmania mitochondria in both models used. In this sense, the assays that we performed provided evidence that the EO caused mitochondrial dysfunction. The first observation was based on the inhibition of oxygen consumption in LtP (Figure 1A). In this model, the EO from T. lucida caused a significant decay of oxygen consumption $(p<0.05)$ compared to untreated parasites at the maximum concentration tested $(100 \mu \mathrm{g} / \mathrm{mL})$, which could suggest that mitochondria constitute an essential target for this EO. Nevertheless, the positive control used (rotenone + antimycin A), showed a higher decrease in oxygen consumption $(p<0.01)$ with respect to untreated parasites or those treated with EO. Second, in the pathogenic $\mathrm{LaP}$, the $\mathrm{EO}$ was able to disrupt the mitochondrial membrane potential (MMP) of the parasite stained with JC-1 (Figure 1B), while for the non-inhibited LaP (negative control), red fluorescence was seen, and for the valinomycin-inhibited (positive control), a green predominant fluorescence was observed.

In contrast, parasites treated with estragole revealed normal oxygen consumption in LtP (Figure 1A), with an inhibition of $<10 \%$ at $100 \mu \mathrm{M}$. Nevertheless, the compound caused a mitochondrial disruption related to MMP in a time-dependent manner in LaP (Figure 1B); although it caused an apparent lower intensity of green fluorescence compared to the EO. This suggests that estragole acts as a mitochondrial uncoupler $(\Delta \psi \mathrm{m})$ but only as a poor inhibitor of the mitochondrial electron transfer in LaP. A potential uncoupling effect of estragole is probably not seen in the oxygen consumption assay because this is superimposed by other components of EO, which inhibit the electron transfer and, therefore, oxygen consumption. This does not exclude that other cellular events could result secondarily in MMP breakdown and mitochondrial changes. These events could include many harmful effects induced by toxic compounds to Leishmania, such as reactive oxygen species (ROS) that induce oxidative damage in lipids and proteins [24], regulation of intracellular calcium homeostasis [25], inhibition of sterol biosynthesis [26,27], and as an initiator of induced cell death [28,29]. In any case, the dysfunction of this vital organelle would have disastrous consequences on parasite survival [30].

Next, to validate the antileishmanial activity of the EO and estragole, the evaluation was extended to the intracellular amastigote form in an infective model using LaA. In parallel, cytotoxicity was assayed on two macrophage models: PMM and the J774A cell line. In general, LaA were more susceptible to EO and estragole than the promastigote model. As shown in Table 1, estragole was significantly more active $(p<0.05)$ than the EO and caused the same inhibition $(p>0.05)$ compared to pentamidine. In the cytotoxicity assays, estragole also displayed more toxicity $(p<0.05)$ than the $\mathrm{EO}$, but its $\mathrm{CC}_{50}$ values were superior $(p<0.05)$ with respect to pentamidine in both cellular models assayed (Table 1). However, concerning selectivity, slightly different results were obtained in each case. The EO was only able to surpass an SI $>10$ with respect to the J774A cells; while estragole and pentamidine displayed a higher SI with PMM as the reference.

According to the criteria of De Lima et al. [31], the EO-derived natural product from T. lucida could be considered as active ( $\mathrm{IC}_{50}$ value between 10 and $50 \mu \mathrm{g} / \mathrm{mL}$ ) against L. amazonensis. The observed leishmanicidal activity of the EO may be related to the presence of the major chemical constituent (estragole), which exhibited antileishmanial activity in the present study. In addition, Katsuno et al. defined compounds with an $\mathrm{IC}_{50}<10 \mu \mathrm{M}$ against the intracellular form of Leishmania as relevant for antileishmanial drug development [32]. Therefore, estragole $\left(\mathrm{IC}_{50}=9.6 \mu \mathrm{M}\right)$ would be of interest for further studies. In addition, estragole exhibits other generic features as a hit candidate for infectious diseases, which include (i) a known chemical structure, (ii) availability from chemical manufacturers or from the EO with a purity $>90 \%$ in both cases, (iii) conformity with 'rule of five' due to $<5 \mathrm{H}$-bond donors, $<10 \mathrm{H}$-bond acceptors, a molecular weight $<500 \mathrm{~g} / \mathrm{mol}$, and a $\log \mathrm{P}<5$ [33], and (iv) a selectivity $>10$ in comparison with mammalian cell models [32]. In addition, relevant differences in 
cytotoxic effects between EO and estragole were appreciated. The occurrence of possible antagonism or compensation of toxic effects by components of EO should be analyzed. Although minor constituents represented a small percentage in the oil, the large number of identified compounds could interfere with membrane viscosity/permeability, disrupt protective effects, regulate some biochemical pathways, or block receptors [34].

A

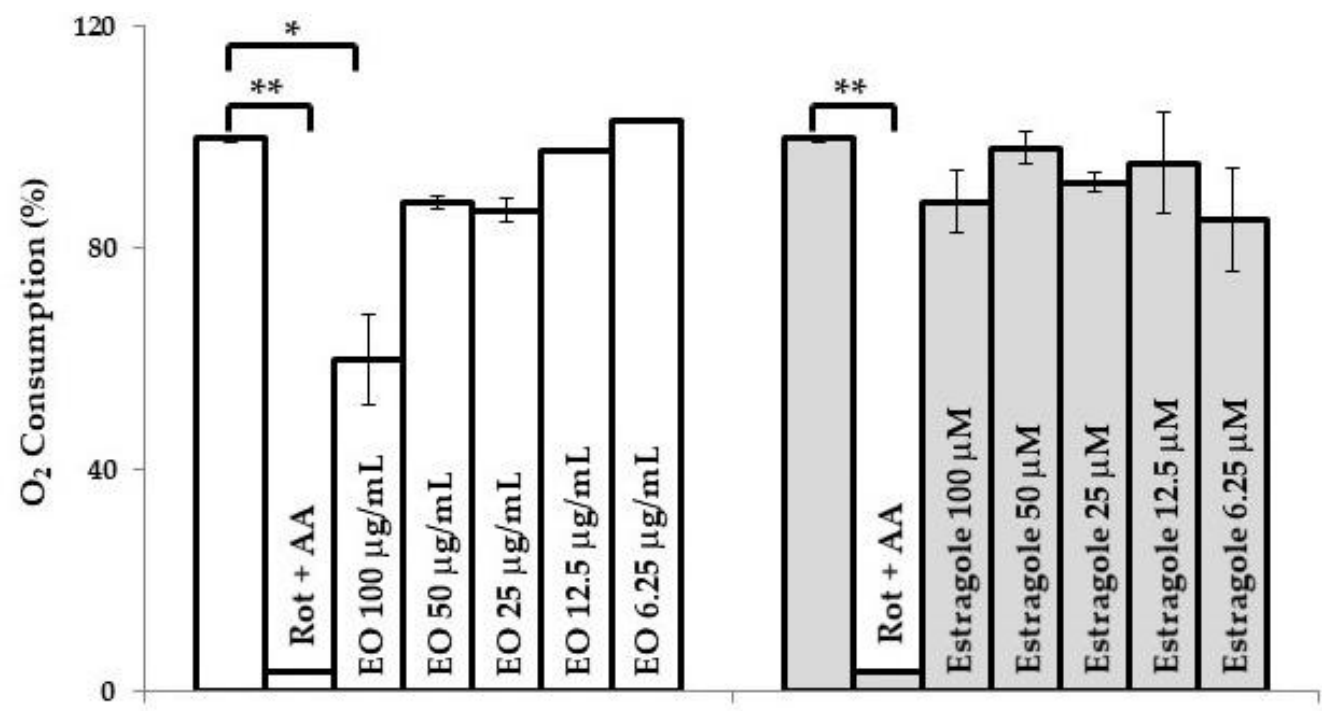

Promastigotes of Leishmania tarentolae

B

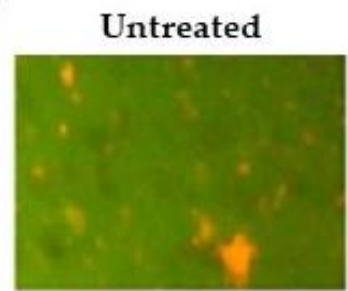

Valinomycin

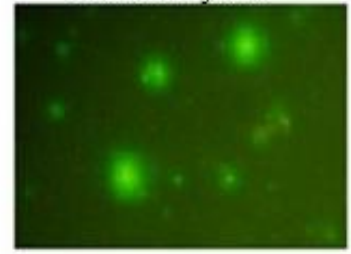

EO $-4 h$

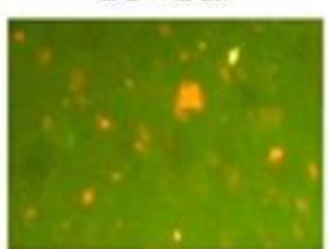

Estragole - $4 \mathrm{~h}$

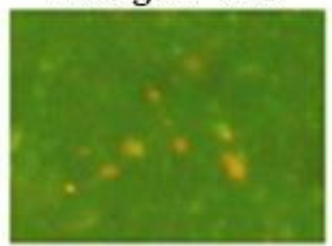

EO $-24 h$

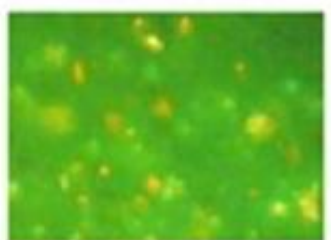

Estragole $-24 \mathrm{~h}$

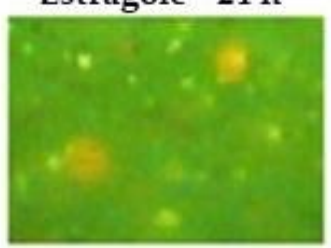

EO - $48 \mathrm{~h}$

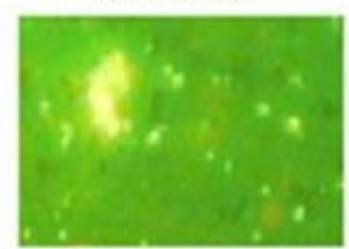

Estragole $-48 \mathrm{~h}$

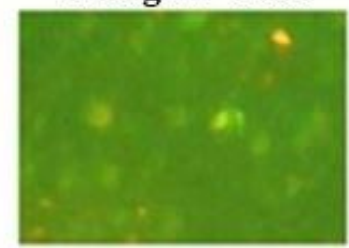

Figure 1. Influence of essential oil from Tagetes lucida Cav. and estragole on mitochondrial function. (A): Oxygen consumption (\%) of Leishmania tarentolae promastigotes measured with OxoPlates. Untreated parasites in brain heart infusion medium served as a reference at $0 \mu \mathrm{g} / \mathrm{mL}(100 \%$ of oxygen consumption), while rotenone $(4 \mu \mathrm{M})$ and antimycin $\mathrm{A}(4 \mu \mathrm{M})$ were included as positive controls. Data are shown as the mean and standard deviation of two replicates. ${ }^{*}$ indicates significant differences $(p<0.05)$ with respect to the reference control parasites; ${ }^{* *}$ indicates significant differences $(p<0.01)$ with respect to the reference control parasites. (B): Mitochondrial membrane potential of L. amazonensis promastigotes was assayed by the JC- 1 dye probe (400× magnification). Cultures of untreated parasites in Schneider's medium and parasites treated with valinomycin at $5 \mu \mathrm{M}$ were included as controls. Green color corresponds to JC-1 monomers, indicating low membrane potential and the orange color indicates JC-1 aggregates, which are formed in mitochondria with high membrane potential because the membrane potential drives JC-1 accumulation. AA: Antimycin A; Rot: Rotenone; EO: Essential oil from T. lucida. 
Table 1. Antileishmanial activity against intracellular amastigotes of Leishmania amazonensis, cytotoxic effects on macrophages, and selectivity of the essential oil from Tagetes lucida Cav., estragole, and pentamidine.

\begin{tabular}{|c|c|c|c|c|c|}
\hline \multirow{2}{*}{ Products } & \multirow{2}{*}{$\begin{array}{c}\mathrm{IC}_{50} \pm \mathrm{SD} \\
\mathrm{LaA}\end{array}$} & \multicolumn{2}{|c|}{$\mathrm{CC}_{50} \pm \mathrm{SD}$} & \multicolumn{2}{|c|}{ SI } \\
\hline & & PMM & J774A & PMM & J774A \\
\hline EO from T. lucida & $14.2 \pm 1.6^{\mathrm{a}} \mu \mathrm{g} / \mathrm{mL}$ & $80.8 \pm 3.6^{a} \mu \mathrm{g} / \mathrm{mL}$ & $156.0 \pm 4.5^{\mathrm{a}} \mu \mathrm{g} / \mathrm{mL}$ & 6 & 11 \\
\hline Estragole & $\begin{array}{c}1.4 \pm 0.1^{\mathrm{b}} \mu \mathrm{g} / \mathrm{mL} \\
9.6 \pm 0.9 \mu \mathrm{M}\end{array}$ & $\begin{array}{c}20.6 \pm 0.8^{\mathrm{b}} \mu \mathrm{g} / \mathrm{mL} \\
139.1 \pm 5.7 \mu \mathrm{M}\end{array}$ & $\begin{array}{c}14.5 \pm 0.4^{\mathrm{b}} \mu \mathrm{g} / \mathrm{mL} \\
97.8 \pm 2.4 \mu \mathrm{M}\end{array}$ & 15 & 6 \\
\hline Pentamidine & $\begin{array}{c}1.3 \pm 0.1^{\mathrm{b}} \mu \mathrm{g} / \mathrm{mL} \\
3.8 \pm 0.3 \mu \mathrm{M}\end{array}$ & $\begin{array}{c}13.6 \pm 0.4^{\mathrm{c}} \mu \mathrm{g} / \mathrm{mL} \\
39.9 \pm 1.1 \mu \mathrm{M}\end{array}$ & $\begin{array}{c}8.1 \pm 2.8^{\mathrm{c}} \mu \mathrm{g} / \mathrm{mL} \\
23.8 \pm 4.1 \mu \mathrm{M}\end{array}$ & 11 & 6 \\
\hline
\end{tabular}

$\mathrm{IC}_{50}$ : Concentration of product that caused $50 \%$ of inhibition of growth of Leishmania promastigotes. SD: Standard deviation. $\mathrm{CC}_{50}$ : Concentration of product that caused $50 \%$ of mortality of peritoneal macrophage from BALB/c mice and J774 cells. SI: selectivity index: $\mathrm{CC}_{50} / \mathrm{IC}_{50}$ against amastigotes $(\mu \mathrm{g} / \mathrm{mL})$. LaA: Intracellular amastigotes of L. amazonensis. PMM: Peritoneal macrophages from BALB/c mice. J774A: Macrophages cell culture. Different letters designate statistical differences $(p<0.05)$ among the $\mathrm{IC}_{50}$ or $\mathrm{CC}_{50}(\mu \mathrm{g} / \mathrm{mL})$ of different products in the same tested model. Pentamidine: Reference drug.

Another aspect to take into account is the observed enhanced activity against the intracellular amastigotes by either $\mathrm{EO}$ or estragole, which could suggest that antileishmanial activities of the $\mathrm{EO}$ and estragole may be related not only to direct action against the parasite, but also to indirect mechanisms. In this sense, other biological properties of estragole have been described, including anti-inflammatory and anti-edematogenic activities [22], which could be positive in the control of some infectious diseases, such as cutaneous leishmaniasis.

In conclusion, although the T. lucida essential oil and estragole were less active than the reference drug, the results obtained in this work confirm the importance of chemical and biological investigations of EO-derived compounds from natural sources as antileishmanial alternatives. Additional research in exploring the antileishmanial mechanism(s) of estragole is needed. Further studies in animal models experimentally infected with L. amazonensis should be performed to demonstrate the observed in vitro antileishmanial potential of these products. To our knowledge, this is the first report of the antileishmanial activity of the EO from T. lucida and its main compound estragole.

Supplementary Materials: The following are available online at http://www.mdpi.com/2218-0532/88/3/31/s1, S1. Materials and Methods: S1.1. Plants and EO from T. lucida, S1.2. Chemical characterization of EO from T. lucida, S1.3. Estragole, S1.4. Parasites and culture, S1.5. Macrophages, S1.6. In vitro antipromastigote activity, S1.7. Mitochondrial function assessment, S1.8. In vitro anti-amastigote activity, S1.9. Cytotoxicity assay, S1.10. Statistical analysis, References for Materials and Methods; Table S1: Chemical composition of essential oil from Tagetes lucida Cav. from Cuba.

Author Contributions: Conceptualization, L.M. (Lianet Monzote); Methodology, L.M. (Lianet Monzote), Y.G., L.M. (Laura Machin), K.S., R.S. and P.S.; Software, W.N.S.; Formal Analysis, W.N.S. and L.G.; Investigation, all authors; Resources, Y.G. and R.S.; Writing-Original Draft Preparation, L.M. (Lianet Monzote); Writing—Review \& Editing, W.N.S. and L.G.; Project Administration, L.M. (Lianet Monzote) and L.G.; Funding Acquisition, L.G. All authors have read and agreed to the published version of the manuscript.

Funding: This research was funded by Austrian Science Fund (FWF), grant number P 27814-B22, and the Ernst Mach scholarship award to Lianet Monzote by the Austrian Exchange Office (OEAD).

Acknowledgments: This work was carried out in collaboration as members of the Research Network Natural Products against Neglected Diseases (ResNetNPND, http://www.resnetnpnd.org/Start/) and contribution of the project Aromatic Plant Research Center (APRC, https://aromaticplant.org/).

Conflicts of Interest: The authors declare no conflict of interest. 


\section{Abbreviations}

$\begin{array}{ll}\Delta \psi \mathrm{m} & \text { Variation of mitochondrial membrane potential } \\ \text { aBHI } & \text { BHI medium saturated with air } \\ \text { BHI } & \text { brain heart infusion } \\ \text { CC }_{50} & \text { Median cytotoxic concentration } \\ \text { CEI-IPK } & \text { Institutional Ethical Committee from the Institute of Tropical Medicine Pedro Kouri } \\ \text { dBHI } & \text { BHI medium reduced with dithionite } \\ \text { DMEM } & \text { Dulbecco's modified eagle medium } \\ \text { DMSO } & \text { Dimethyl sulfoxide } \\ \text { EO } & \text { Essential oil } \\ \text { GC-MS } & \text { Gas chromatography-mass spectrometry } \\ \text { HFBS } & \text { Heat-inactivated fetal bovine serum } \\ \text { IC } & \text { Median inhibitory concentration } \\ \text { JC-1 } & \text { 5,5',6,6'-Tetrachloro-1,1',3,3'-tetraethyl-benzimidazolylcarbocyanine iodide } \\ \text { LaA } & \text { Leishmania amazonensis amastigotes } \\ \text { LaP } & \text { Leishmania amazonensis promastigotes } \\ \text { LtP } & \text { Leishmania tarentolae promastigotes } \\ \text { MMP } & \text { Mitochondrial membrane potential } \\ \text { MTT } & \text { 3-(4,5-Dimethylthiazol-2-yl)-2,5-diphenyltetrazolium bromide } \\ \text { PBS } & \text { Phosphate buffered saline } \\ \text { PMM } & \text { Peritoneal macrophage from mice } \\ \text { ROS } & \text { Reactive oxygen species } \\ \text { SD } & \text { Standard deviation } \\ \text { SI } & \text { Selectivity index } \\ \text { YEM } & \text { Yeast extract medium }\end{array}$

\section{References}

1. Burza, S.; Croft, S.L.; Boelaert, M. Leishmaniasis. Lancet 2018, 392, 951-970. [CrossRef]

2. Meira, C.M.; Gedamu, L. Protective or detrimental? Understanding the role of host Immunity in leishmaniasis. Microorganisms 2019, 7, 695. [CrossRef] [PubMed]

3. Gradoni, L. Canine Leishmania vaccines: Still a long way to go. Vet. Parasitol. 2015, 208, 94-100. [CrossRef] [PubMed]

4. Bekhit, A.A.; El-Agroudy, E.; Helmy, A.; Ibrahim, T.M.; Shavandi, A.; Bekhit, A.E.A. Leishmania treatment and prevention: Natural and synthesized drugs. Eur. J. Med. Chem. 2018, 5, 229-244. [CrossRef] [PubMed]

5. Simoben, C.V.; Ntie-Kang, F.; Akone, S.H.; Sippl, W. Compounds from African medicinal plants with activities against selected parasitic diseases: Schistosomiasis, trypanosomiasis and leishmaniasis. Nat. Prod. Bioprospect. 2018, 8, 151-169. [CrossRef] [PubMed]

6. Moraes Neto, R.N.; Setúbal, R.F.B.; Higino, T.M.M.; Brelaz-de-Castro, M.C.A.; Da Silva, L.C.N.; Aliança, A.S.S. Asteraceae plants as sources of compounds against leishmaniasis and Chagas disease. Front. Pharm. 2019, 10, 477. [CrossRef]

7. Pérez-Ortega, G.; González-Trujano, M.E.; Ángeles-López, G.E.; Brindis, F.; Vibrans, H.; Reyes-Chilpa, R. Tagetes lucida Cav.: Ethnobotany, phytochemistry and pharmacology of its tranquilizing properties. J. Ethnopharmacol. 2016, 181, 221-228. [CrossRef]

8. Bonilla-Jaime, H.; Guadarrama-Cruz, G.; Alarcon-Aguilar, F.J.; Limón-Morales, O.; Vazquez-Palacios, G. Antidepressant-like activity of Tagetes lucida Cav. is mediated by 5-HT(1A) and 5-HT(2A) receptors. J. Nat. Med. 2015, 69, 463-470. [CrossRef]

9. Gutiérrez, G.Y.; Scull, L.R.; Montes, A.A.; García, S.G. Pharmacognostic, phytochemical and biological evaluation of a hydroalcoholic extract of Tagetes lucida Cavanilles. Rev. Cub. Plantas Med. 2018. Available online: http://revplantasmedicinales.sld.cu/index.php/pla/article/view/669 (accessed on 28 July 2020).

10. Regalado, E.L.; Fernández, M.D.; Pino, J.A.; Mendiola, J.; Echemendia, O.A. Chemical composition and biological properties of the leaf essential oil of Tagetes lucida Cav. from Cuba. J. Essent. Oil Res. 2011, 23, $63-67$. [CrossRef] 
11. Omer, E.A.; Hendawy, S.F.; Ismail, R.F.; Petretto, G.L.; Rourke, J.P.; Pintore, G. Acclimatization study of Tagetes lucida L. in Egypt and the chemical characterization of its essential oils. Nat. Prod. Res. 2017, 31, 1509-1517. [CrossRef] [PubMed]

12. Bandeira Reidel, R.V.; Nardoni, S.; Mancianti, F.; Anedda, C.; El Gendy, A.E.G.; Omer, E.A.; Pistelli, L. Chemical composition and antifungal activity of essential oils from four Asteraceae plants grown in Egypt. Z. Nat. C J. Biosci. 2018, 73, 313-318. [CrossRef] [PubMed]

13. Caballero-Gallardo, K.; Olivero-Verbel, J.; Stashenko, E.E. Repellent activity of essential oils and some of their individual constituents against Tribolium castaneum Herbst. J. Agric. Food Chem. 2011, 59, 1690-1696. [CrossRef] [PubMed]

14. Cicció, J.F. A source of almost pure methyl chavicol: Volatile oil from the aerial parts of Tagetes lucida (Asteraceae) cultivated in Costa Rica. Rev. Biol. Trop. 2004, 52, 853-857. [PubMed]

15. Zarate-Escobedo, J.; Castañeda-González, E.L.; Cuevas-Sánchez, J.A.; Carrillo-Fonseca, C.L.; Ortiz-Torres, C.; Ibarra-Estrada, E.; Serrato-Cruz, M.A. Essential oil of some populations of Tagetes lucida Cav. from the northern and southern regions of the state of México. Rev. Fitotec. Mex. 2018, 41, 199-209.

16. López López, E.; Peña Ortega, M.G.; Colinas León, M.T.B.; Díaz Cedillo, F.; Serrato Cruz, M.A. Fungistasis of essential oil extracted from a Tagetes lucida population of Hidalgo, México. Rev. Mex. Cienc. Agric. 2018, 9, 329-341.

17. Zarate-Escobedo, J.; Castañeda-González, E.L.; Cuevas-Sánchez, J.A.; Carrillo-Fonseca, C.L.; Mendoza-Garcia, E.E.; Serrato-Cruz, M.A. Concentrations and application intervals of the essential oil of Tagetes lucida Cav. against Nacobbus aberrans. Rev. Mexicana Cienc. Agric. 2018, 9, 589-600.

18. Hernandez-Leon, A.; González-Trujano, M.E.; Narváez-González, F.; Pérez-Ortega, G.; Rivero-Cruz, F.; Aguilar, M.I. Role of $\beta$-caryophyllene in the antinociceptive and anti-inflammatory effects of Tagetes lucida Cav. essential oil. Molecules 2020, 25, 675. [CrossRef]

19. Khan, A.; Ahmad, A.; Khan, L.A.; Manzoor, N. Ocimum sanctum (L.) essential oil and its lead molecules induce apoptosis in Candida albicans. Res. Microbiol. 2014, 165, 411-419. [CrossRef]

20. Mota, M.L.; Lobo, L.T.; Costa, J.M.; Costa, L.S.; Rocha, H.A.; Rocha e Silva, L.F.; Pohlit, A.M.; Neto, V.F. In vitro and in vivo antimalarial activity of essential oils and chemical components from three medicinal plants found in northeastern Brazil. Planta Med. 2012, 78, 658-664. [CrossRef]

21. Jitviriyanon, S.; Phanthong, P.; Lomarat, P.; Bunyapraphatsara, N.; Porntrakulpipat, S.; Paraksa, N. In vitro study of anti-coccidial activity of essential oils from indigenous plants against Eimeria tenella. Vet. Parasitol. 2016, 228, 96-102. [CrossRef] [PubMed]

22. Rodrigues, L.B.; Oliveira Brito Pereira Bezerra Martins, A.; Cesário, F.R.; Ferreira E Castro, F.; de Albuquerque, T.R.; Martins Fernandes, M.N.; Fernandes da Silva, B.A.; Quintans Júnior, L.J.; da Costa, J.G.; Melo Coutinho, H.D.; et al. Anti-inflammatory and antiedematogenic activity of the Ocimum basilicum essential oil and its main compound estragole: In vivo mouse models. Chem. Biol. Interact. 2016, 257, 14-25. [CrossRef] [PubMed]

23. Al-Musayeib, N.M.; Mothana, R.A.; Matheeussen, A.; Cos, P.; Maes, L. In vitro antiplasmodial, antileishmanial and antitrypanosomal activities of selected medicinal plants used in the traditional Arabian Peninsular region. BMC Complement. Altern. Med. 2012, 12, 49. [CrossRef] [PubMed]

24. Britta, E.A.; Scariot, D.B.; Falzirolli, H.; Ueda-Nakamura, T.; Silva, C.C.; Dias Filho, B.P.; Borsali, R.; Nakamura, C.V. Cell death and ultrastructural alterations in Leishmania amazonensis caused by new compound 4-nitrobenzaldehyde thiosemicarbazone derived from S-limonene. BMC Microbiol. 2014, 14, 236. [CrossRef] [PubMed]

25. Dolai, S.; Pal, S.; Yadav, R.K.; Adak, S. Endoplasmic reticulum stress induced apoptosis in Leishmania through $\mathrm{Ca}^{2+}$-dependent and caspase independent mechanism. J. Biol. Chem. 2011, 286, 13638-13646. [CrossRef]

26. Serrano-Martín, X.; García-Marchan, Y.; Fernandez, A.; Rodriguez, N.; Rojas, H.; Visbal, G.; Benaim, G. Amiodarone destabilizes intracellular $\mathrm{Ca}^{2+}$ homeostasis and biosynthesis of sterols in Leishmania mexicana. Antimicrob. Agents Chemother. 2009, 53, 1403-1410. [CrossRef]

27. Macedo-Silva, S.T.; Silva, T.L.A.O.; Urbina, J.Á.; De Souza, W.; Rodrigues, J.C.F. Antiproliferative, ultrastructural, and physiological effects of amiodarone on promastigote and amastigote forms of Leishmania amazonensis. Mol. Biol. Int. 2011, 876021-876112. [CrossRef]

28. Ly, J.D.; Grubb, D.R.; Lawen, A. The mitochondrial membrane potential (deltapsi(m)) in apoptosis; an update. Apoptosis 2003, 8, 115-128. [CrossRef] 
29. Green, D.R.; Kroemer, G. The pathophysiology of mitochondrial cell death. Science 2004, 305, 626-629. [CrossRef]

30. Dos Santos, A.O.; Costa, M.A.; Ueda-Nakamura, T.; Dias-Filho, B.P.; da Veiga-Júnior, V.F.; de Souza Lima, M.M.; Nakamura, C.V. Leishmania amazonensis: Effects of oral treatment with copaiba oil in mice. Exp. Parasitol. 2011, 129, 145-151. [CrossRef]

31. De Lima, J.P.S.; Pinheiro, M.L.B.; Santos, A.M.G.; Pereira, J.L.S.; Santos, D.M.F.; Barison, A.; Silva-Jardim, I.; Costa, E.V. In vitro antileishmanial and cytotoxic activities of Annona mucosa (Annonaceae). Rev. Virtual Quim. 2012, 4, 692-702. [CrossRef]

32. Katsuno, K.; Burrows, J.N.; Duncan, K.; van Huijsduijnen, R.H.; Kaneko, T.; Kita, K.; Mowbray, C.E.; Schmatz, D.; Warner, P.; Slingsby, B.T. Hit and lead criteria in drug discovery for infectious diseases of the developing world. Nat. Rev. Drug. 2015, 14, 751-758. [CrossRef] [PubMed]

33. Lipinski, C.A.; Lombardo, F.; Dominy, B.W.; Feeney, P.J. Experimental and computational approaches to estimate solubility and permeability in drug discovery and development settings. Adv. Drug Deliv. Rev. 2012, 64, 4-17. [CrossRef]

34. Edris, A.E. Pharmaceutical and therapeutic potentials of essential oils and their individual volatile constituents: A review. Phytother. Res. 2007, 21, 308-323. [CrossRef] [PubMed]

(C) 2020 by the authors. Licensee MDPI, Basel, Switzerland. This article is an open access article distributed under the terms and conditions of the Creative Commons Attribution (CC BY) license (http://creativecommons.org/licenses/by/4.0/). 